\title{
A PRÁTICA PEDAGÓGICA COM ALUNO SURDO NO ENSINO FUNDAMENTAL I
}

\section{PEDAGOGICAL PRACTICE WITH DEAF STU- DENTS IN ELEMENTARY SCHOOL I}

\author{
Lucinéa da Silva Dias ${ }^{1}$ \\ Eloisa Helena Mello²
}

\begin{abstract}
Resumo: O presente artigo tem como objetivo pesquisar como acontece a prática pedagógica no Ensino Fundamental I para alunos surdos, destacando a importância da valorização da educação especial e como os professores regentes de sala da aula proporcionam a inclusão alinhando a sua prática pedagógica de forma integrada a realidade vivenciada por seus educandos. Para a realização deste trabalho que é de cunho qualitativo e se fez neces-

sário uma pesquisa bibliográfica, ou seja, uma pesquisa detalhada com materiais de grande relevância, levantamento bibliográfico, trazendo os conceitos dos principais autores para esse tema, com a proposta de aprofundar, enriquecendo a discussão ao tema estudado, através de estudos e referências bibliográficas de autores de grande expressão na área educacional, fundamentada em leitura e reflexão de livros, artigos e sites, em que foi utilizado
\end{abstract}

1 Aluna do Curso de Licenciatura em Pedagogia do Centro Universitário Internacional UNINTER

2 Professora Orientadora do Centro Universitário Internacional UNINTER

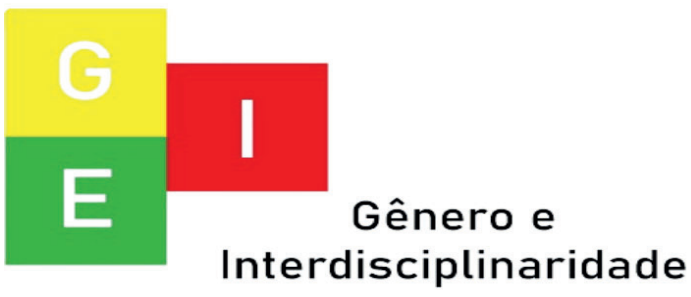


ISSN: 2675-745

Vol. 02 - n 03 - ano 202

Editora Acadêmica Periodicoj

na produção este trabalho. No processo de escolha do material, ocorreu uma análise significativa de tudo que foi elaborado, buscando a melhor compreensão do mesmo, detectando as melhores referências a serem aplicadas, na produção do artigo, levando em consideração a necessidade do tema para a educação do surdo. Sobretudo, principalmente, no currículo voltado a essa questão e, aos pedagogos. Este estudo possibilitou novos conhecimentos acerca da educação especial e inclusiva na pesquisa e na prática.

Palavras chaves: Prática Pedagógica. Inclusão. Educação Especial.

Abstract: This article aims to research how the pedagogical practice happens in Elementary School I for deaf students, highli- ghting the importance of valuing special education and how classroom teachers provide inclusion, aligning their pedagogical practice in an integrated way with reality experienced by their students. In order to carry out this work, which is of a qualitative nature, a bibliographical research was necessary, that is, a detailed research with highly relevant materials, a bibliographic survey, bringing the concepts of the main authors to this theme, with the proposal to deepen, enriching the discussion of the studied theme, through studies and bibliographical references of authors of great expression in the educational area, based on reading and reflection of books, articles and websites, in which this work was used in the production. In the process of choosing the material, there was a significant analysis of everything that was prepared,

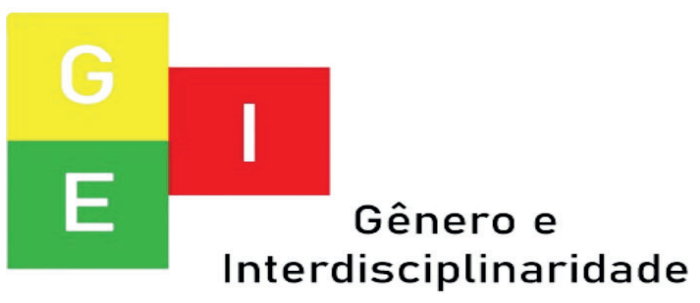


ISSN: 2675-7451

Vol. 02 - n 03 - ano 2021

Editora Acadêmica Periodicojs

seeking a better understanding of

it, detecting the best references

to be applied in the production

of the article, taking into accou-

$\mathrm{nt}$ the need for the topic for deaf

education. Above all, especially

in the curriculum aimed at this

issue and at pedagogues. This

study provided new knowledge

about special and inclusive education in research and practice.

Keywords: Pedagogical Practice. Inclusion. Special education.

\section{INTRODUÇÃO}

A realização desta pesquisa proporcionou a reflexão e estudo acerca do tema: A prática pedagógica com aluno surdo no ensino fundamental I. E qual a importância das práticas pedagógicas para alunos surdos no ensino fundamental I? Essa é uma indagação que tem levado os aca-

dêmicos e profissionais da educa-

ção a aprofundar seus estudos em busca de respostas.

Esta pesquisa tem como objetivos: Pesquisar como funcionam as metodologias aplicadas na sala de aula com os alunos surdos; relatar sobre as práticas pedagógicas no ensino fundamental I, para o ensino com alunos surdos e analisar como funciona a inclusão de surdo na rede regular de ensino.

O trabalho de conclusão de curso aqui apresentado é expresso por meio de estudo e análise bibliográfica, realizada por meio de leituras sobre o tema descrito acima.

No processo de escolha deste material para a realização desta pesquisa, houve uma análise de tudo que foi estudado, tentando por meio do mesmo, revelar as melhores referências como

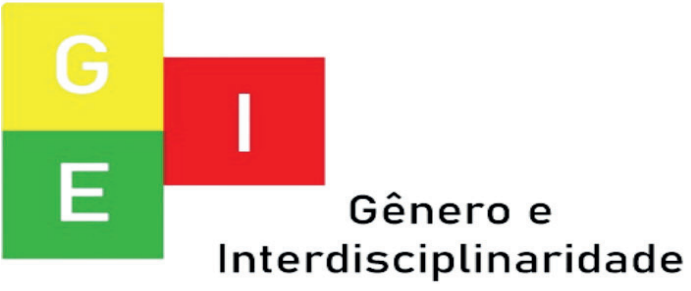


ISSN: 2675-745

Vol. 02 - n 03- ano 202

Editora Acadêmica Periodicoj

abordagem de conhecimentos a serem utilizados na produção do trabalho.

Esse trabalho é importante para prática pedagógica pois, os educadores irão refletir num planejamento adaptado que atenda os alunos surdos. A qualificação do professor (a) é muito importante para o desenvolvimento da aprendizagem dos discentes surdos, ao trabalhar a sua língua materna, mostrando de forma coerente, o nível de desenvolvimento dos mesmos, com um ensino que atenda as devidas necessidades, promovendo acessibilidade e a capacidade que o aluno tem em seu nível de aprendizagem.

É de suma importância, descobrir como se dá a prática pedagógica nessa etapa de ensino. Qual seja o Fundamental I, tendo em vista, o público alvo, os educandos surdos, tendo como foco, o funcionamento das metodologias aplicadas em sala de aula, relatando sobre as ações pedagógicas, diante do público em questão. E, também, analisar como funciona a inclusão de surdo, na rede regular de ensino.

O tema dessa pesquisa delimitou na busca de conhecimento sobre as práticas pedagógicas para atender as particularidades dos alunos surdos matriculados no ensino fundamental I, e requer um olhar diferenciado dos docentes, buscando uma estratégia que promova a inclusão dos mesmos, em sala de aula, por meio de adaptação dos componentes curriculares existentes.

Este trabalho está estruturado de forma que os primeiros subtemas trazem fundamentos de autores e estudiosos que abordam sobre a educação especial e inclusiva no contexto educacional

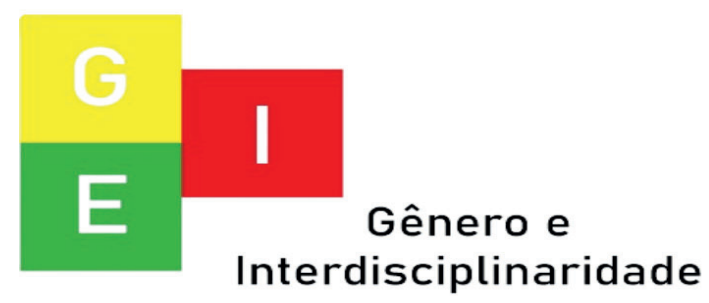


ISSN: 2675-7451

Vol. 02 - n 03 - ano 2021

Editora Acadêmica Periodicojs

e escolar, seu percurso educativo, a educação de surdos; seguindo com a metodologia adotada, considerações finais e referências bibliográficas, tudo embasado em teóricos que abordam o tema descrito.

EDUCAÇÃO ESPECIAL E INCLUSIVA NO CONTEXTO EDUCACIONAL E ESCOLAR

Breve percurso da educação especial

Para melhor compreender o desenvolvimento da Educação Especial e Inclusiva no contexto educacional, vamos abordar uma breve explanação desse artigo. Pesquisar como funcionam as metodologias aplicadas na sala de aula com os alunos surdos.

As práticas pedagógicas no ensino fundamental I para o ensino com alunos surdos na rede pública se dá através de um bom planejamento escolar com material adaptado: recursos tecnológicos como suporte para aulas em Libras, facilitando o entendimento do aluno surdo, jogo de memória, cartaz com ilustração das imagens, material concreto, lúdico, para o visual por consequência a sinalização, e os professores devem ser criativos e comprometidos ao atendimento desse aluno com qualidade, atendendo seu direito previsto pela lei. Em favorecimento a todos, tanto na escola como na sociedade em geral deve ter pessoas capacitadas, para atender e mediar os surdos. Já paramos para pensar se tudo fosse transmitido em Libras, pois é, sentiremos excluídos, por isso devemos pensar em uma educação de qualidade e com equidade.

Analisar como funciona a inclusão de surdo na rede regu-

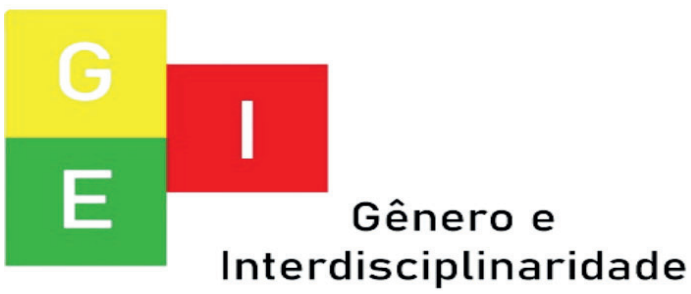


ISSN: 2675-745

Vol. 02 - n 03 - ano 202

Editora Acadêmica Periodico

lar de ensino, pois é de grande importância para os pedagogos estarem preparados ao exercer seu papel de professor (a) onde atenda todos seus alunos com eficiência, tendo conhecimento e qualificação, sendo assim os mesmos terão seu desenvolvimento adequado e seus direitos dentro do contexto escolar. Os pedagogos antes de assumir a sala de aula têm que investigar a melhor maneira de incluir o aluno surdo na rede regular de ensino, onde ele consiga acompanhar a turma. Quanto antes à criança tiver contato com sua Língua materna, maior será o seu desenvolvimento no processo cognitivo.

A exclusão real se concretiza na impossibilidade de que alunos com graves comprometimentos físicos e/ ou intelectuais frequentem escolas públicas com profissionais e pro- posta pedagógicas adequadas as suas necessidades, usufruindo de recursos de acessibilidade, tecnologia assistiva e serviços médicos e terapêuticos que complementem a escolarização. Impossibilita, ainda que surdos tenham a sua diferença linguística respeitada pela oferta de escolas bilíngue e intérpretes da Língua Brasileira de Sinais (Libras) para a apropriação do conhecimento. (FERNANDES, 2013, p.105).

Para que realmente aconteça a apropriação do conhecimento para o público que apresenta algum tipo de deficiência é essencial que a inclusão saia da teoria e ocorra na prática. Para a efetivação do conhecimento, é necessário quebrar todos os tipos de barreiras desde as arquitetôni-

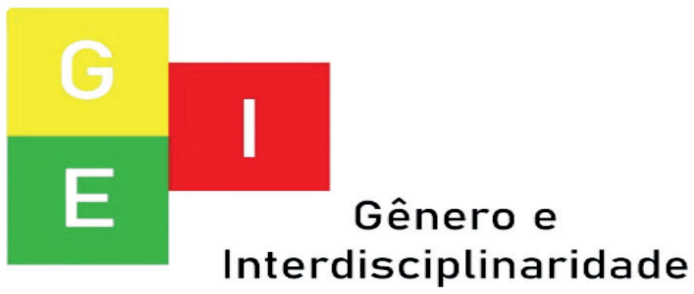


ISSN: $2675-7451$

Vol. 02 - n 03- ano 2021

Editora Acadêmica Periodicojs

cas até no que tange a formação do professor e sua prática no cotidiano escolar.

No entanto, para que a inclusão dos estudantes Surdos em salas comuns aconteça é necessário planejar e debater, especialmente sobre as práticas pedagógicas e a formação do professor, para atender as particularidades desses estudantes, pois o que se deseja não é apenas a integração, mas a inclusão pela qual os estudantes possam obter conhecimento sem restrições por meio de uma inserção total. Entretanto, nem sempre acontece dessa forma, já que grandes são as transformações ideológicas que chegam à escola, porém as velhas práticas precisam ser refletidas.

Para a concretização da educação inclusiva é imprescindível que haja uma prévia atualização das práticas pedagógicas, com redefinições que exceda o ambiente escolar, implementando projetos educativos inclusivos, com políticas educacionais, fazendo mudanças e reorganização que vise a contemplação da inclusão e atenda a todos com qualidade, adequando, assim, a escola ao aluno e não esse ter que se adaptar a escola.

As práticas desenvolvidas com alunos surdos na escola regular ainda utilizam estratégias pedagógicas formuladas para ouvintes, o que dificulta muito a aprendizagem dos surdos. Considerando-se o atual contexto educacional do país, verifica-se uma política de integração que está organizada para atender a todos os alunos. No entanto, as escolas ainda se valem de práticas consideradas tradicionais, desconsiderando o aluno

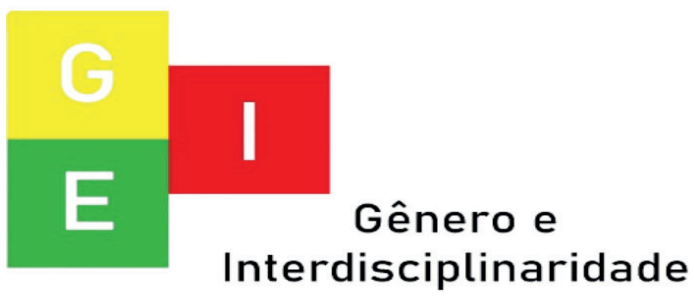


Vol. 02 - n 03 - ano 202

Editora Acadêmica Periodicoj

como ser em desenvolvimento, com vivências, habilidades

e especificidades cognitivas próprias. Tais práticas determinam que o aluno seja quem deve ser adaptar à escola, conquistando sua oportunidade de estar na sala de aula, tendo que provar sua capacidade em acompanhar as atividades propostas. Nesse caso, parece que o caminho mais certo para o aluno seja a exclusão do espaço escolar. (BETIM, 2013, p.15)

Infelizmente essas práticas pedagógicas ainda são vivenciadas no meio educacional, e a exclusão da pessoa com deficiência vem tomando espaço dia a dia. Ter educação de qualidade é direito de todo cidadão isso a lei garante. Há saberes diferentes e aprendizagens em seu deter- minado tempo, isso tem que ser respeitado e avaliado de forma igualitária, porém diferenciada. A escola deve ser a facilitadora a abrir caminhos para essas pessoas se sentirem os próprios construtores de suas histórias para assim se sentirem capazes e incluídos no meio social.

Sabe-se que nem sempre a educação de surdos foi considerada como uma prática aceitável na sociedade, mas com a evolução o espaço da comunidade surda vem conquistando seu direito de repensar num ensino que atenda a todos. Por longo período de tempo, a surdez ou qualquer outro tipo de necessidade especial era vista com maus olhos, onde a deficiência era dita como uma anormalidade dentro do padrão social.

Durante muitas décadas na história, a educação especial não foi valorizada nem mesmo

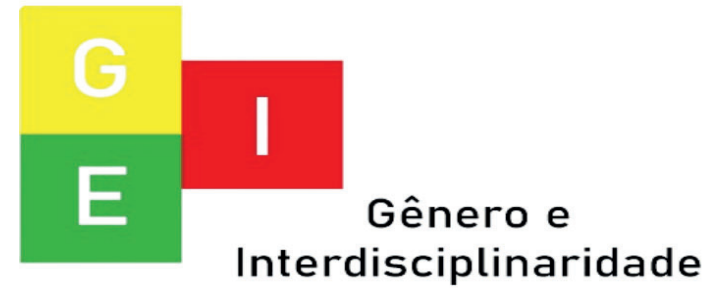


ISSN: 2675-7451

Vol. 02 - n 03 - ano 2021

Editora Acadêmica Periodicojs

reconhecida pela sociedade, devendo percorrer um árduo e incessante trabalho para modificar os conceitos trazidos ao longo do tempo.

$\mathrm{Na}$ antiguidade as pessoas que nascessem com deficiências eram condenadas à morte ou abandono, a surdez era considerada anomalia, diziam que a pessoa que nascia surda estava recebendo um castigo, sendo reconhecido como louco ou defeituoso.

Atualmente, crianças e jovens com necessidades especiais são vistos como pessoas capazes de contribuir significativamente no contexto social, enriquecendo as experiências dos indivíduos que com eles convivem.

As mudanças desse contexto de aceitação foram alcançadas graças aos esforços de médicos e pedagogos que desafiaram os conceitos da época em que a discriminação e o preconceito reinavam em torno das pessoas com necessidades especiais.

Vale ressaltar que na atualidade a escola exerce um papel de extrema importância no processo de inclusão desses indivíduos possuintes de necessidades educacionais especiais, na sociedade. Entretanto, já houve tempos em que ela própria praticava o ato de discriminação e segregação de pessoas com deficiências.

A educação inclusiva veio após um longo caminho de lutas pelo ingresso e ressignificação da prática educativa, na qual buscava atender a todos de forma igualitária e não houvesse discriminação.

O grande desafio do momento atual é oferecer uma escola de qualidade para todos, reconhecendo as singularidades de cada aluno, considerando sua

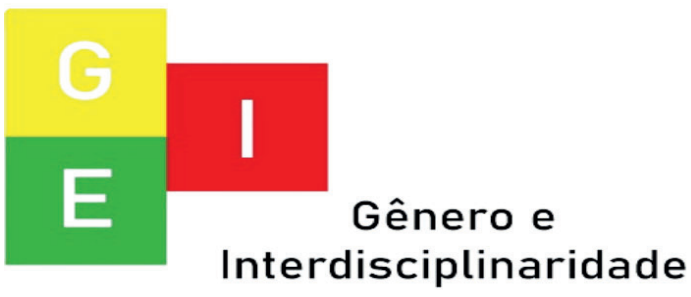


ISSN: 2675-745

Vol. 02 - n 03 - ano 202

Editora Acadêmica Periodico

individualidade e aproveitando da diversidade para enriquecer o contexto educativo, construindo um espaço não apenas de aprendizagens educativas escolares, como também de valorização, cidadania e respeito.

O movimento pela inclusão teve maior repercussão no século $\mathrm{XX}$, esse período se caracterizou pelo início da obrigatoriedade e da expansão da escolarização básica. Após essa iniciativa, surgiram alunos que necessitavam de acompanhamento das suas dificuldades de aprendizagem, carecendo de um olhar mais atencioso a estes que não conseguiam andar no mesmo ritmo dos demais.

A inclusão não acontece somente pelo fato de o aluno com necessidade especial estar matriculado e frequentando uma escola de ensino regular ou um ambiente educacional especial.
A inclusão se dá mediante ao acolhimento desse indivíduo, ao trabalho inclusivo e ao incentivo que o levará a percorrer uma trajetória acadêmica que alcance êxito igualmente a toda comunidade escolar.

$\mathrm{Na}$ atualidade, ainda é possível encontrar professores que se apresentam resistentes a trabalhar com alunos que apresentam necessidades educacionais especiais, talvez devido ao conhecimento restrito sobre as deficiências e as possibilidades/ habilidades do sujeito com alguma limitação ou ao receio de expor sua fragilidade teórica.

Contudo, faz-se necessária a realização de formações continuadas com $o$ intuito de sensibilizar e conscientizar os professores da necessidade de inclusão, além de oferecer condições de traba-

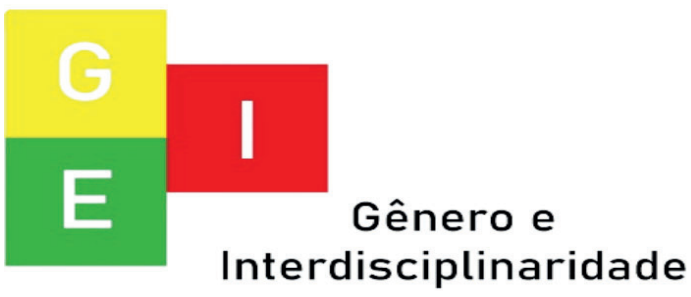


ISSN: $2675-7451$

Vol. 02 - n 03 - ano 2021

Editora Acadêmica Periodicojs

lho aos profissionais da educação, visando contribuir para uma prática pedagógica que contemple as necessidades dos educandos, fazendo uma associação entre teoria e prática. $\mathrm{Na}$ realidade com a qual nos defrontamos, os alunos surdos inserem-se na sala de aula regular ainda com muitas dificuldades. As políticas de inclusão desses e outros - alunos no espaço escolar não dão conta de preparar e instrumentalizar a escola e o professor para proporcionar-lhes um ensino de qualidade, respeitando suas possibilidades e peculiaridades cognitivas. $\mathrm{O}$ que se tem visto é que muitos professores, além de não se sentirem preparados, não querem sentir-se responsáveis pela educação dos alunos surdos, marginalizando-os das aulas, utilizando métodos desenvolvidos para os ouvintes. Permitimo-nos inferir, inclusive, que mesmo com todas as condições ideais para inclusão desses alunos, a boa vontade do professor sempre se constituirá como fator fundamental. (BETIM, 2013, p.1819)

Outro ponto relevante neste contexto é que o professor esteja em constante processo de aprendizado, no qual ele possa refletir sobre sua prática, reconhecendo os desafios da sua atuação, pontuando os problemas que são referentes aos seus conhecimentos e reconhecendo que esses problemas não são exclusivamente inerentes a sua competência, cabendo atribuir a cada

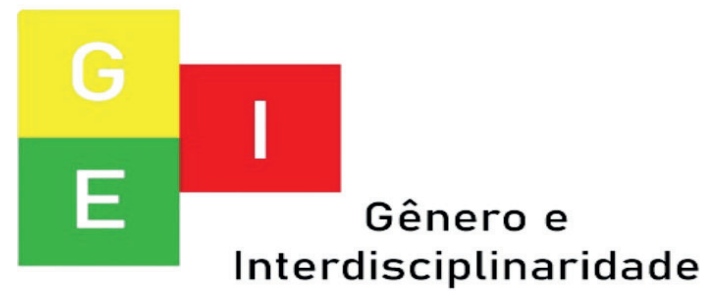


ISSN: 2675-745

Vol. 02 - n 03 - ano 202

Editora Acadêmica Periodicoj

envolvido nesse processo, uma parte dessa questão.

A escola na condição de ambiente de formação deve estar apta a atender a todos de maneira igualitária, banindo a exclusão e adotando de forma espontânea o processo de acolhimento, o cuidado amplo não apenas no sentido de incluir pessoas com deficiências, como também respeitar e valorizar as particularidades de cada sujeito que nela se encontra.

Esta forma de entender a inclusão reivindica a noção de pertencer, uma vez que considera a escola como uma comunidade acolhedora em que participam todas as crianças. [...]. De igual forma, cuida para que ninguém seja excluído por suas necessidades especiais, ou por pertencer a grupos éticos ou linguísticos minoritários, por não

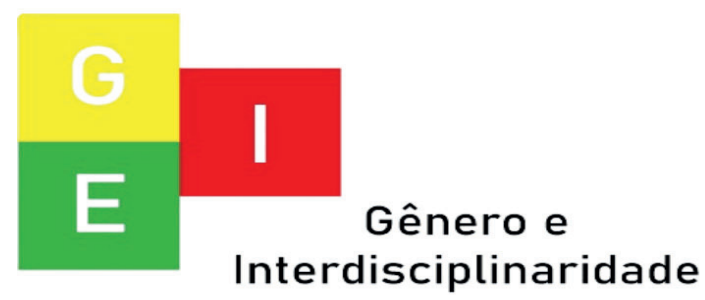
ir frequentemente a aula, e, finalmente, ocupa-se dos alunos em qualquer situação de risco. (SÁNCHEZ 2005, p.13).

Dessa forma, a escola é considerada uma instituição de acolhimento, que cuida dos estudantes que a ela pertencem, promovendo a inclusão, não permitindo que o fato de a pessoa apresentar algum tipo de deficiência seja motivo de exclusão. Mas que tenha uma prática de ensino que atenda todos com qualidade visando um olhar diferenciado procurando sempre os melhores recursos e estratégias de ensino, professores que faz a diferença na vida dos alunos que busca aperfeiçoamento para que os mesmo tenha sua aprendizagem no tempo certo, para que o mesmo se sinta acolhido e não fique segregado. 
A escola que adota a que têm fortes impactos sobre as educação inclusiva, muito contri- pessoas com necessidades espebui para a formação do cidadão ciais, onde a falta de informações mais crítico e reflexivo pelo fato leva o indivíduo à exclusão, não de durante o processo educativo (re) conhecendo os seus direitos poder vivenciar a prática incluna sociedade e por consequência siva, o zelo pelo seu semelhante, acabam perdendo seus direitos ampliando os horizontes de todos como cidadão.

os envolvidos, demonstrando que Outro desafio é referena exclusão não é a melhor opção a te ao fracasso e a evasão escolar se fazer em relação a pessoa com por parte de alunos que apresendeficiência, porque o crescimento tam dificuldades no processo de acontece mediante as diferenças. aprendizagem, esses problemas O movimento pela insão decorrentes de fatores e que clusão tem contribuído para a são oriundos das péssimas condiampliação da escola no contexto ções pedagógicas e socioeconôeducativo e no processo de ensino e aprendizagem, sendo toda micas que os tornam desfavorecidos.

comunidade escolar contemplada

Algumas ações de recom os benefícios das ações inclusivas presentes e praticadas no ambiente escolar.

O processo de inclusão ainda enfrenta inúmeros desafios, nos quais é possível elencar a pobreza e a desigualdade social, ceptividade e acolhimento são desenvolvidas para promover o processo de inclusão, garantindo, assim, a integração de pessoas com deficiências.

O espaço educacional do surdo está cada vez mais se

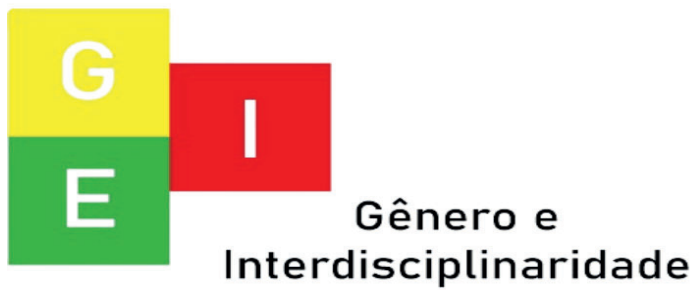


ISSN: 2675-745

Vol. 02 - n 03 - ano 202

Editora Acadêmica Periodico

preparando e buscando melhores propostas educacionais para atender as necessidades dos educandos, investindo em formação de professores e profissionais especializados para oferecer um ensino de qualidade.

Com a evolução e o aperfeiçoamento das propostas educacionais para a educação de surdos, uma grande parte das escolas de surdos tem tentado implantar um projeto de educação que possibilite ao aluno adquirir os saberes universalmente acumulados através da língua de sinais e que leve em consideração a experiência visual de ser surdo, por isso, a presença do professor surdo oferece um elemento positivo para as crianças surdas ali atendidas, porque elas se identificam melhor com ele, podendo gerar melhor compreensão e aprendizagem.

A luta pela inclusão tem sido incessante, o enfrentamento de desafios demanda muito jogo de cintura, além de ser impactante para aqueles que dela precisam. Muitos jovens com necessidades especiais sofrem discriminação e preconceitos no meio social, contudo, eles devem ser preparados e orientados a reagirem diante dessas situações desagradáveis de forma a não causar baixa autoestima. A valorização das diferenças é algo que deve ser debatido e exposto em todos os ambientes educacionais e sociais com o intuito de conscientizar e minimizar os transtornos.

$\mathrm{Na}$ escola inclusiva,
pressupõe-se uma concepção cuja práxis tenha como princípio o compromisso com a qualidade de uma sólida formação integral ao aluno, oferecendo conhecimentos que lhe sirvam à análise e reflexão crítica acerca da realidade em que se insere, de modo a

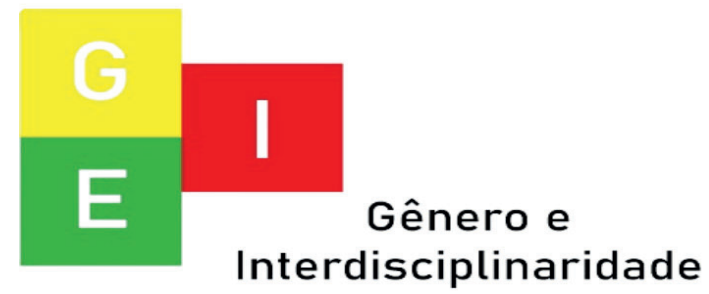


ISSN: 2675-7451

Vol. 02 - n 03 - ano 2021

Editora Acadêmica Periodicojs

contribuir para a consolidação de

uma sociedade que supere, definitivamente, desigualdades sociais. É nessa escola que educadores comprometidos acreditam.

Em se tratando de educação e escola inclusiva, vale ressaltar que a língua de sinais precisa se fazer presente nas unidades escolares como forma de reconhecimento da identidade da pessoa com surdez, contribuindo assim para a formação concreta do indivíduo.

[...] uma criança adquire sua primeira língua - L1 - de forma natural e espontânea, ou seja, essa língua não é ensinada: ninguém ensina ninguém a falar, simplesmente se aprende a falar. Da mesma forma com as crianças surdas, ninguém ensina a sinalizar, mas de forma natural se aprende a sinalizar. As crianças, quando chegam à escola, já sabem falar. Com as crianças surdas, filhos de pais surdos, isso também acontece, pois adquirem naturalmente a língua de sinais; portanto, essa é a L1 dessas crianças. Entretanto, elas representam somente $5 \%$ das crianças surdas, isto é, a maioria das crianças surdas são filhas de pais ouvintes. Dessa forma, normalmente as crianças não dispõem da língua de sinais para desenvolvê-la como L1 e, consequentemente, chegam à escola sem dominar nenhuma língua. Tendo em mente os objetivos a que a escola se propõe, todos os esforços devem voltar-se para que a criança tenha a oportunidade de adquirir sua primeira língua - L1 (QUADROS, 1997a,

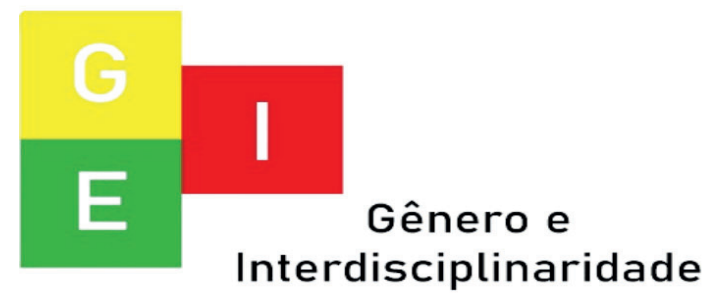


p. 108).

A criança aprende com seus familiares gestualização caseira, o que dificultaria o trabalho do professor de Libras para o ensino de sua Língua, mas a escola utilizará as melhores estratégias para proporcionar o ensino da língua de sinais (Libras) para que os alunos surdos possam se apropriar desde o início da vida escolar, uma vez que eles já chegam à escola recebendo sua aprendizagem na sua Língua materna o mesmo vai desenvolver sua comunicação e aprendizagem benéfica e sem ser prejudicado.

Os professores enfrentam um desafio em relação ao material didático e pedagógico para atender alunos surdos, no ensino regular, pelo fato da educação bilíngue ser recente no país, no entanto, buscam alternativas na organização de materiais que visem a inserção desses alunos no meio educacional, não o deixando excluído dos demais.

Além disso, os recursos de apoios especializados oferecidos pela educação especial são fundamentais e indispensáveis elementos atuantes necessários para a participação de todos os alunos durante as atividades realizadas na unidade escolar.

Assim sendo, não basta que os professores tenham consciência da necessidade de inclusão, é preciso que sua formação continuada ofereça subsídio que suscite novas possibilidades de mediação no tocante a prática pedagógica, proporcionando análise e reflexão sobre suas condições de trabalho.

Por outro lado, nos centros de educação especial o ensino torna-se mais satisfatório e prazeroso por dispor de profissionais especializados, de materiais

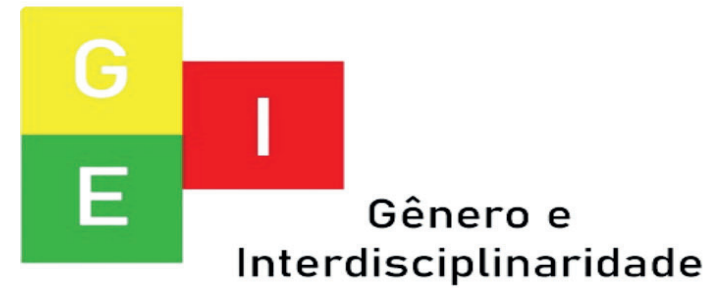


ISSN: 2675-7451

Vol. 02 - n 03 - ano 2021

Editora Acadêmica Periodicojs

didáticos e pedagógicos, recursos

e um currículo organizado para atender as especificidades dos estudantes e suas necessidades educativas.

No século XX a educação especial foi reconhecida como modalidade de educação escolar, com isso a escola regular passou a compartilhar algumas das preocupações em relação ao atendimento especializado, que se dava em torno da proposição de metodologias específicas, adaptações didáticas, dificuldades de aprendizagem, atendendo as particularidades em suas singularidades, respeitando as diferenças individuais de cada sujeito.

A realização da escola inclusiva pressupõe a compreensão sócio-histórica das deficiências, ou seja, que o conceito de deficiência se constitui socialmente e pode ser superado, se adequados forem os processos de mediação social na reversão das limitações impostas pelas condições orgânicas iniciais. Significa dizer que as singularidades manifestadas pelos alunos, em função de quadros orgânico-funcionais oriundos de deficiências e ou transtornos globais no desenvolvimento, demandarão recursos e serviços complementares àqueles utilizados na educação comum, para os pares da mesma faixa etária, na apropriação do conhecimento.

O ambiente escolar necessita de algumas mudanças para ser um espaço que de fato promova a inclusão, é preciso fazer adaptações físicas no local, como barreiras, rampas, corrimões, além de contar com profissionais especializados na área, os currículos devem se flexíveis, dentre outras adequações.

Mesmo contando com

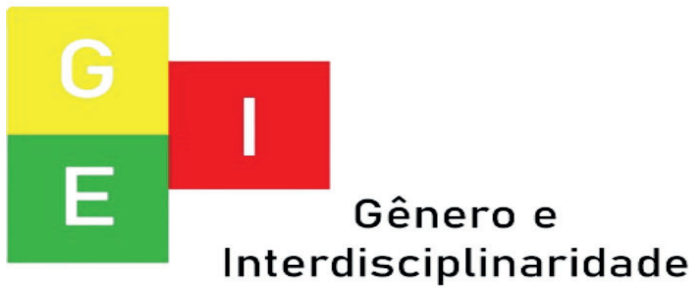


ISSN: 2675-745

Vol. 02 - n 03 - ano 202

Editora Acadêmica Periodicoj

uma boa estrutura física, com profissionais qualificados e um currículo flexível, essa unidade não será inclusiva se ela não acolher o aluno respeitando suas singularidades. A inclusão só acontece mediante um conjunto de ações nas quais contemple a todos de forma unificada no sentido da igualdade e da equidade.

O movimento pela inclusão traz como apelo a atenção social a esses alunos oriundos de grupos sociais que passaram a compor a diversidade escolar, entre eles, aqueles com deficiências, desafiando os sistemas de ensino a redimensionar as políticas curriculares e as práticas docentes.

\section{A Educação de Surdos}

Antes de iniciar a abordagem acerca da educação de surdos, faz-se necessário conhe- cer um pouco sobre a Língua Brasileira de Sinais (Libras), a reconhecida como, primeira Língua do surdo.

A língua de sinais difere das línguas orais pelo fato da utilização da visão e do espaço para sua realização, e não do canal oral-auditivo. Sua modalidade de manifestação acontece através da realização de sinais utilizando as mãos, o corpo e expressões, onde os gestos e a visão são predominantes para que a comunicação aconteça.

A Educação bilíngue no Brasil é advinda de influências de países como Estados Unidos e Suécia, nos quais a educação de surdos deixou de ser centrada na fala e na escrita da língua oral, passando a adotar e aplicar a língua de sinais.

A inserção de duas línguas no ambiente escolar ainda é algo que merece um olhar mais

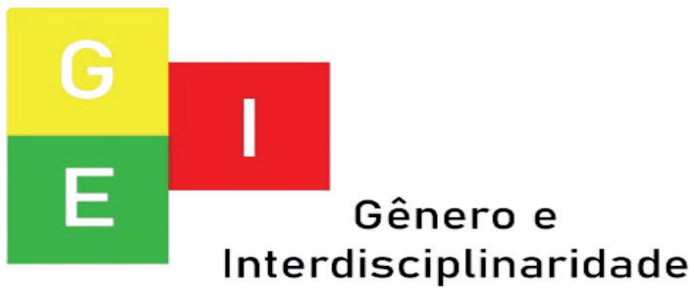


ISSN: 2675-7451

Vol. 02 - n 03 - ano 2021

Editora Acadêmica Periodicojs

atento, pelo fato da necessidade de atender a todos de forma igualitária e promover a inclusão, faz-se necessário adotar o bilinguismo na educação formal.

$\mathrm{O}$ indivíduo desenvolverá formas diferenciadas de bilinguismo. A primeira delas é o bilinguismo aditivo, na qual as duas línguas são suficientemente valorizadas no desenvolvimento cognitivo da criança e a aquisição da L2 ocorre, consequentemente, sem perda ou prejuízo da L1. No entanto, na segunda forma de aquisição, denominada bilinguismo subtrativo, a primeira língua é desvalorizada no ambiente infantil, gerando desvantagens cognitivas no desenvolvimento da criança e neste caso durante a aquisição da L2 ocorre perda ou prejuízo da
L1 (MEGALE, 2005, p.8-9).

Portanto, a inserção do bilinguismo no contexto educacional desde a educação infantil torna a aprendizagem ainda mais significativa, levando a criança a desenvolver a cognição sem prejuízo, obtendo a compreensão e valorização tanto da língua materna quanto da segunda língua.

$\mathrm{Na}$ educação de surdos a Libras tem importância primária em seu uso, sendo a linguagem oral considerada a segunda língua pelo fato do impedimento auditivo dos educandos. Assim, cabe à escola o difícil papel de motivar e garantir que os surdos conheçam a oralidade, valorizando a diversidade linguística.

Sendo assim, o professor assume um papel de suma importância na ação me-

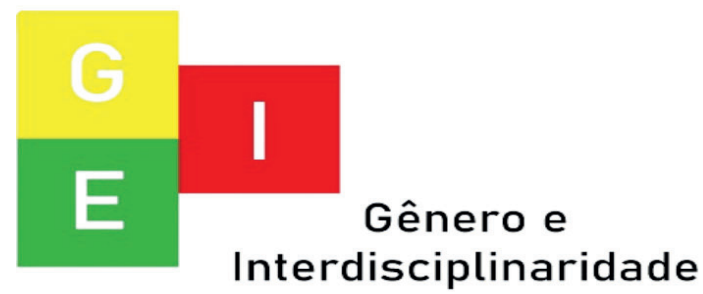


diadora promovendo a prática inclusiva, a valorização das mais diversas culturas no contexto educacional.

A escola deve ser um ambiente que não cabe a exclusão, seu papel é formadora do sujeito crítico e reflexivo, conhecedor da diversidade cultural existentes no meio educacional e social, que lute por transformações que irão beneficiar os menos favorecidos, banindo a desigualdade econômica e social, ampliando os horizontes no campo da inclusão, conscientizando a todos da importância da igualdade de direitos e oportunidades.

Nesse contexto, os professores muitas vezes se veem defronte de situações de inclusão de alunos surdos, e por não serem capacitados nessa especialidade, buscam alternativas de incluir esse indivíduo de forma equivocada, porém, para isso, faz-se necessário que haja um planejamento prévio e cuidadoso em relação a essa inserção, para que não acarrete em mal entendido, levando o aluno a evasão ou abandono escolar.

Segundo Albres e Saruta (2012, p.21):

Passa-se a exercer uma reflexão sobre a língua, pela qual o indivíduo adquire uma identidade intelectual, e passa a ter várias compreensões daquilo que lhe é apresentado, construindo valores e significados de acordo com suas experiências. É na e pela língua que os surdos constroem e constituem sua identidade e valorizam sua história em condição de minoria linguística.

É de fundamental importância que a educação de surdo se dê em sua língua materna

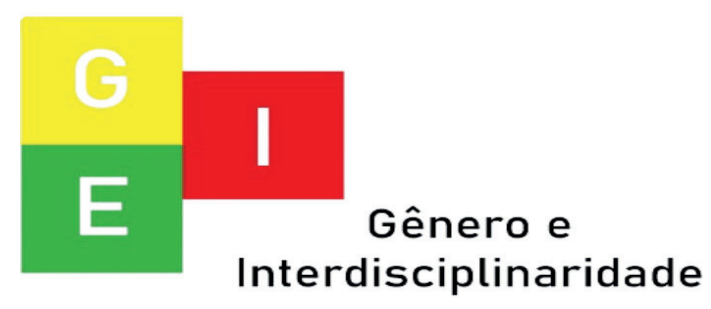


Vol. 02 - n 03 - ano 2021

Editora Acadêmica Periodicojs

neste caso a Libras, levando em consideração que o aluno com deficiência auditiva ou surdez aprendendo no seu campo espaço visual, o professor junto com o intérprete de Libras se faz necessário trazer os componentes curriculares de forma objetiva em que os alunos possam ver compreender e entender a interpretação e tradução de forma clara, para que haja uma evolução significativa no seu ensino aprendizado, e por fim acontecendo à inclusão e mais acessibilidade a toda comunidade surda.

Segundo Fernandes (2013, p.91), “Com a ausência de investimentos em políticas de acessibilidade para pessoas com deficiência, elas se tornam impedidas de realizar atividades esportivas ou de lazer, por falta de condições estruturais".

Por falta de investimento as pessoas com deficiência são prejudicadas dentro do seu meio social, perdendo seu direito ao frequentar a escola, esporte, lazer. Sendo necessários recursos adaptados que possibilitariam superar esses desafios: rampas de acesso aos cadeirantes transportes adaptados, prótese auditiva, softwares educativos, a educação bilíngue para surdos, e, além disso, é necessário o acompanhamento de profissionais como o intérprete de Libras material visual para facilitar o entendimento do surdo em sala de aula, material em braile para cegos.

O fato de ter uma deficiência não quer dizer que é incapaz, pois dentro de suas limitações possui suas capacidades superando os obstáculos. Assim sendo, as pessoas com deficiência encontram diariamente diversos obstáculos, essas ausências de acessibilidade às impedem de realizar suas atividades cotidia-

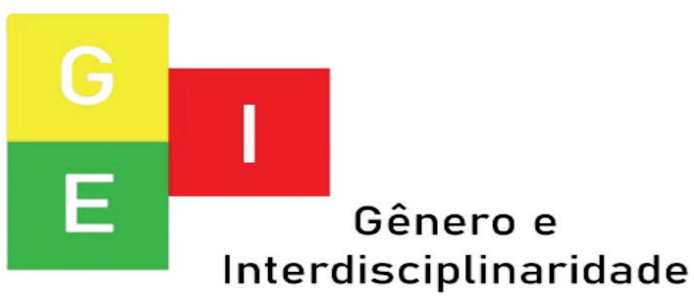


nas deixando-as em situação de vulnerabilidade.

Haja Vista que na lei tem as portarias que dão direito aos recursos adaptados. Porém na prática isso na maioria das vezes não acontece, permanecendo apenas na teoria. A inclusão de alunos com deficiência no âmbito escolar é um debate atual, o aluno com necessidade especial precisa de mais cuidado e atenção para poder acompanhar o aprendizado da turma, a escola deverá estar preparada para utilizar os mais variados recursos destinados para os principais tipos de deficiência, cada qual com sua especificidade.

O aluno com deficiência tem o direito de ser respeitado e ter tratamento diferenciado, para isso é preciso pessoas capacitadas para prestar atendimentos adequados. Não só no espaço escolar, mas em qualquer ambien- te precisa de acessibilidade para qualquer tipo de deficiência. Por força da política nacional de inclusão, estudantes surdos têm que concluir seus estudos em escolas nos quais todo o ensino é oferecido em língua portuguesa, sem a presença de intérpretes (ou outros profissionais de apoio) e sem as adequações curriculares necessárias que levem em consideração sua singularidade linguística. (FERNANDES 2006, p.06).

Levando em consideração o exposto acima por Fernandes fica claro o quanto as políticas nacionais de inclusão precisam melhorar, o aluno surdo sem acompanhamento de interprete e sem ter os componentes curriculares adaptados para sua língua materna terá sua forma-

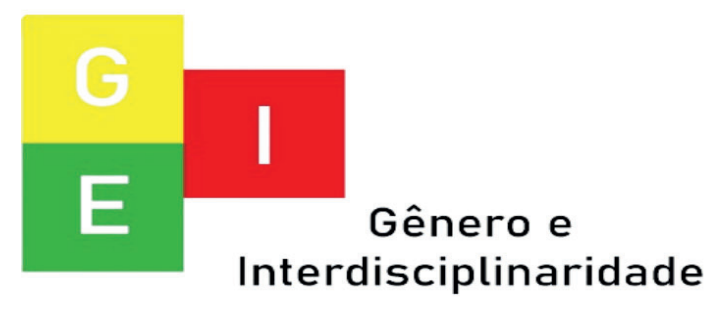


ISSN: 2675-7451

Vol. 02 - n 03 - ano 2021

Editora Acadêmica Periodicojs

ção escolar prejudicada, pois não conseguiram aprender usando o português oral devido a sua deficiência ser ligada aos canais auditivos, provavelmente passaram de ano concluíram todas as etapas da educação infantil, fundamental e médio sem desenvolver seu aprendizado possivelmente apenas alunos copistas, ou seja, copiam o que estiver exposto no quadro porém em entendimento algum do que foi escrito. É com base em situações como essas que se faz necessário uma adequação dos componentes curriculares a existência de intérpretes e professores de apoio que venha sanar ou diminuir os prejuízos de uma educação que não visa atender as particularidades dos alunos neste caso os educandos surdos.

Para que o ensino-aprendizagem ocorra é necessário que a escola entenda que somente a inserção do intérprete de Libras não é o suficiente para a garantia deste processo, pois além deste profissional, é preciso diversas mudanças, tais como: Adaptação do currículo, mudanças no planejamento do professor regente, oferta do Atendimento Educacional Especializado no contraturno para o ensino de Libras e português na modalidade escrita, e a produção de recursos visuais e adaptados para uso nas diversas atividades no ambiente escolar.

Além destas questões, é importante que a Libras seja ofertada aos alunos ouvintes, principalmente as turmas que receberão surdos, pois a interação deve ocorrer não somente entre intérprete de Libras, professor de Libras e alunos surdo, se faz necessário a comunicação entre os alunos surdos e ouvintes para que o aluno surdo se sinta parte da escola.

A singularidade dos alu-

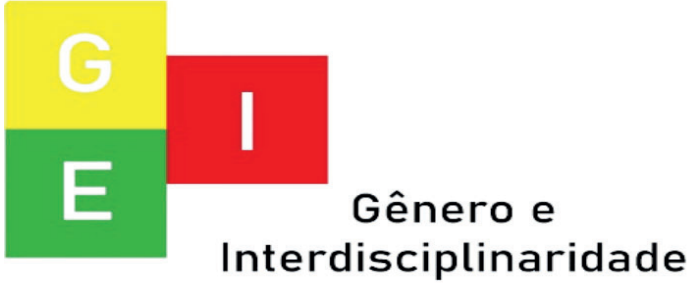


ISSN: 2675-745

Vol. 02 - n 03 - ano 202

Editora Acadêmica Periodicoj

nos surdos tem como pressuposto a implementação de uma proposta da educação bilíngue, que contemple a interação e a mediação da aprendizagem realizada pela utilização de duas línguas em sua escolarização: a língua brasileira de sinais - Libras e a Língua portuguesa.

Mesmo assim, a maioria dos encaminhamentos metodológicos envolvendo alunos surdos utiliza-se dos mesmos recursos e estratégias realizadas na alfabetização de crianças e jovens não surdos, pressupondo a oralidade como requisito fundamental ao domínio da escrita. (FERNANDES, 2006).

De acordo com os estudos realizados, essa metodologia utilizada em sala de aula é prejudicial ao entendimento dos alunos surdos. Pois o professor muitas vezes utiliza das práticas tradicionais, na qual o aluno tem que se adaptar a escola, quando

o apropriado seria a instituição procurar estratégias que beneficie esse público, com essa situação, acaba ocasionando a evasão escolar desses alunos. Faz-se necessário o professor está sempre buscando conhecimentos, através da formação continuada, e os melhores recursos, pois assim sua aula terá rendimento e interesse por parte das turmas.

As práticas desenvolvidas em sala de aula com aluno surdo no ensino fundamental I ainda utilizam método para ouvintes, com discentes surdos, o que precisa ser revista, pois dificultam a compreensão do mesmo.

Pela estreita relação entre língua-cultura, a comunidade surda politicamente organizada reivindica a escola e as classes bilíngues para surdos como espaço alternativo à sua escolari-

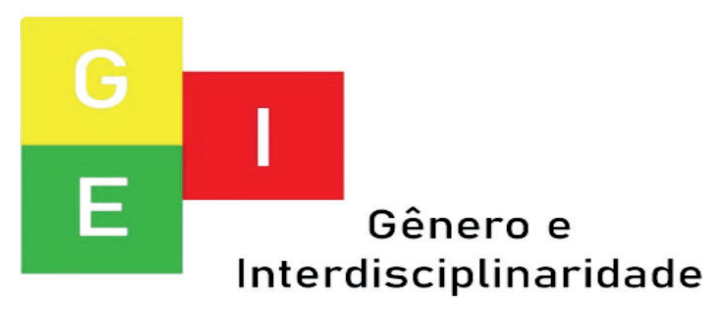


ISSN: $2675-7451$

Vol. 02 - n 03 - ano 2021

Editora Acadêmica Periodicojs

zação. Essa luta histórica vem

ganhando dimensões mundiais

consistentes, alinhando-se ideo-

logicamente às reivindicações de

outros grupos culturais como os

indígenas brasileiros, em detri-

mento de sua planificação e exe-

cução nos limites territoriais da educação especial.

O trabalho do professor surdo é determinante na construção da identidade do ser surdo, por facilitar uma maior aproximação entre ambos, contribuindo significativamente para a apropriação da Libra e o desenvolvimento da linguagem.

[...] a construção da subjetividade do ser surdo depende, fundamentalmente, da relação que eles estabelecem tanto com seus pares quanto com ouvintes e, nesse sentido, a presença de professores surdos na educação ganha relevância para a construção de uma percepção positiva da surdez pelos alunos (LODI, 2005, p. 419).

Assim sendo, é de extrema importância a presença do professor surdo na educação de Surdos, uma vez que, este possui particularidades semelhantes aos alunos, contribuindo para uma melhor compreensão por parte dos estudantes, auxiliando-o a alcançar uma formação mais prazerosa, havendo maior êxito no ensino e na aprendizagem.

A Libras tem para crianças surdas a mesma função que a língua portuguesa, na modalidade oral, tem para ouvintes e, portanto, é ela que vai possibilitar as crianças aprender, inclusive aprender língua portuguesa na modalidade escrita. A Libras é considerada a língua de instrução em todos os componentes

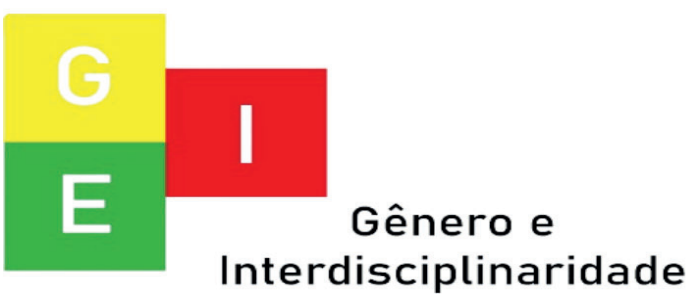


ISSN: 2675-7451

Vol. 02 - n 03 - ano 2021

Editora Acadêmica Periodicojs

curriculares.

Sabe-se que um dos principais avanços garantidos às crianças com necessidades educacionais especiais, é o direito assegurado por lei, do início do atendimento especializado, no qual inicia na educação infantil e perdura por todo o fluxo de escolarização, passando a educação especial a ser inserida em todos os níveis da educação escolar. Com isso, os recursos e serviços da educação especial devem estar disponíveis desde a educação infantil até o nível superior, a todos que dele necessitar.

Essa obviedade não era reconhecida em legislação anteriores, sobretudo sob o modelo da integração, posto que se vinculava a oferta da educação especial às séries iniciais do ensino fundamental. Do mesmo modo, há que se promover a interação entre educação especial com as demais modalidades da educação escolar, como a educação de jovens e adultos, a educação tecnológica, a educação indígena, uma vez que o alunado com necessidades educacionais especiais também se encontra presente nessas modalidades, requerendo o suporte especializado necessário à sua escolarização formal.

Nesse sentido, a língua de sinais exerce não apenas a mera função instrumental de recurso para a leitura do português escrito, mas, sobretudo, de língua que mobilizará as hipóteses dos alunos sobre a constituição de sentidos do texto. Por isso é necessário que a mediação do professor se dê exclusivamente em língua de sinais, a fim de que os alunos não se sintam reprimidos pelas barreiras linguísticas para demonstrar sua opinião e o conhecimento de mundo relacionado ao tema em questão.

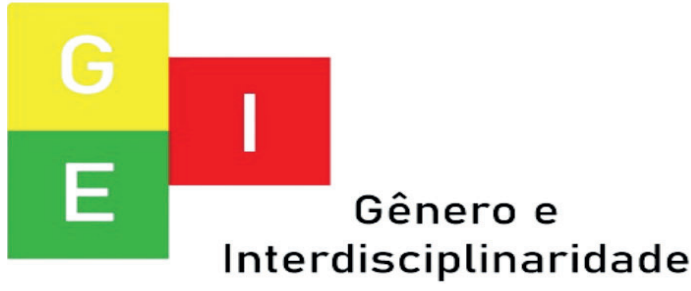


ISSN: $2675-7451$

Vol. 02 - n 03 - ano 2021

Editora Acadêmica Periodicojs

importância do tema para a edu-

cação, sobretudo, principalmente

\section{METODOLOGIA}

O trabalho de conclusão

de curso apresentado é expresso através do estudo de uma pesquisa bibliográfica, realizada em alguns materiais selecionados. Segundo Lakatos e Marconi "toda bibliografia já tornada pública em relação ao tema de estudo [...] Sua finalidade é colocar o pesquisador em contato direto com tudo o que já foi escrito, dito ou filmados sobre determinado assunto". (1991, p. 183).

No processo de escolha de material para as pesquisas houve uma análise de tudo que foi estudado, tentando por meio do mesmo, detectar as melhores referências a serem utilizadas na produção do trabalho. Levando também em consideração a necessidade de pôr em evidência a para o pedagogo e para o profes-

sor.

A análise e estudo dos diversos autores citados no decorrer deste trabalho, proporcionou o relacionamento entre as ideias desenvolvidas com uma abordagem mais qualitativa. Despertando a curiosidade e conhecimentos, embasado em teóricos que descrevem sobre a educação especial e inclusiva.

É importante ressaltar que dentre as informações aqui apresentadas, formam utilizadas aqueles que se relacionavam de maneira mais precisa com o tema, buscando aperfeiçoar os conhecimentos, situar a importância da inserção do lúdico na sala de aula e na construção do desenvolvimento e aprendizagem na educação infantil.

Diante do resultado da

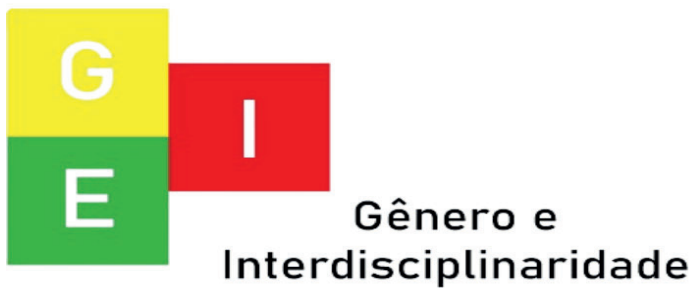


ISSN: $2675-745$

Vol. 02 - n 03 - ano 202

Editora Acadêmica Periodicoj

pesquisa e de tudo que foi descrito baseado em fonte teórica de autores conceituados que reportam a importância do tema e discutem os benefícios que a prática pedagógica voltada para a Educação Especial traz para o desenvolvimento de estudos e beneficia os estudantes com necessidades educativas. Assim no que referem a este estudo, tais teorias me permitiram conhecer o que dizem os teóricos sobre essa temática.

A pesquisa bibliográfica promoveu desafios a serem alcançados sobre várias questões que consequentemente foram relacionados com o processo de ensino-aprendizagem.

Portanto, uma pesquisa qualitativa, na qual visa conhecer mais afundo a realidade em questão, os indicadores coletados intrinsecamente ligados ao cenário de uma escola pública trazem aspectos indissolúveis atrelados às questões históricas que será evidenciado diante do confronto dos dados a tal ponto apenas para emergir a essência do que será aferido pelo estudo.

Espero que essa pesquisa sirva de incentivo para os estudiosos e futuros professores que apreciam e utilizam a educação especial e inclusiva como forma de conhecimento, de maneira a ampliar suas experiências, contribuindo para o processo de ensino e aprendizagem e, ajudando buscar respostas para compreender a importância dessa temática na formação dos indivíduos.

\section{CONSIDERAÇÕES FINAIS}

O propósito desse trabalho se tangencia na compreensão da importância e necessidade do estudo e da prática da educação

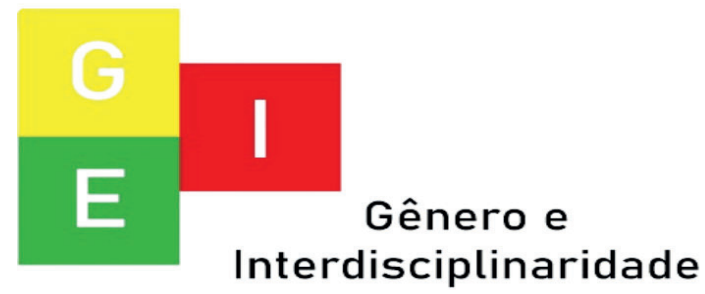


ISSN: 2675-7451

Vol. 02 - n 03 - ano 2021

Editora Acadêmica Periodicojs

especial e inclusiva, em especial para alunos surdos no ensino fundamental I. Ressaltando que os objetivos aqui traçados, foram de certa forma alcançados, uma vez que o estudo e a pesquisa, proporcionaram muitos esclarecimentos referentes ao tema em questão.

Com base na problemática dessa proposta de pesquisa na qual indaga qual a importância das práticas pedagógicas para alunos surdos no ensino fundamental I, foi necessário traçar uma metodologia que fosse possível buscar respostas para essa indagação e também fornecesse subsídios que ampliassem os conhecimentos acerca do tema.

Durante a realização dessa pesquisa, conseguiu-se aprofundar os conhecimentos sobre a educação especial e inclusiva, tendo em vista que a luta pela inclusão é constante e per- manente no contexto histórico e educativo, uma vez que permite uma série de situações no desenvolvimento do aluno, favorecendo a formação do sujeito criativo, reflexivo e transformador.

Entretanto, essa pesquisa possibilitou contribuições significativas para a formação acadêmica e profissional, uma vez que ajudou a compreender a importância em desenvolver um trabalho igualitário e de qualidade que contemple a todos.

Contudo, todas as pesquisas que fiz através de fontes para a construção deste trabalho, ouve discursões sobre o tema onde defende a temática e mostra seus benefícios, mostra que possui uma nova metodologia, mais aprofundada no assunto da Educação Especial e Inclusiva, visando formar cidadãos mais justos e críticos em seus posicionamentos acadêmicos e pessoais.

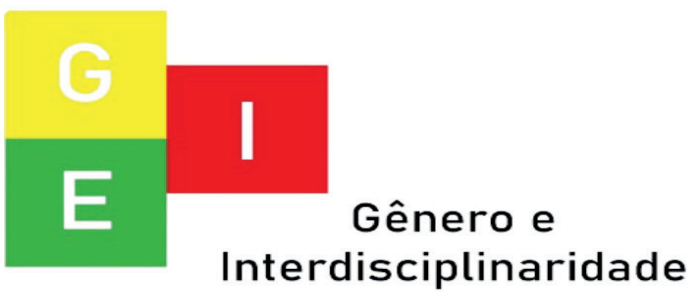




$$
\text { Esse estudo auxiliou vimento. }
$$

bastante na minha trajetória e vida profissional, fortalecendo os meus conhecimentos, onde apreciei ainda mais a importância do estudo e ensino da Educação Especial e Inclusiva dentro do processo de ensino-aprendizagem. Espero que este trabalho possa colaborar junto aqueles que vêm se preocupando com a melhoria do ensino como forma de garantir formação de cidadãos autônomos, críticos que participe da construção de uma sociedade mais justa e igualitária.

Portanto, ficou claro e bem explicado que com essa pesquisa pode ajudar minha vida profissional futuramente, pois percebi e fiz novas descobertas sobre a Educação e sobre o seu ensino na aprendizagem, e espero que, pude colaborar para construí uma sociedade com mais igualdade, e com mais desenvol-

\title{
REFERÊNCIAS
}

\begin{abstract}
ALBRES, N. A. SARUTA, M. V. Programa curricular de língua brasileira de sinais para surdos.
\end{abstract} São Paulo: Ist, 2012.

BAGGIO, M. A.; NOVA, M. da G. C. Libras / [organizado pela] Universidade Luterana do Brasil - Ulbra. - Curitiba: Ibpex, 2009. BERGAMO, Regiane Banzzatto. Educação Especial: pesquisa e prática. - Curitiba: InterSaberes, 2012. - (Série Inclusão Escolar).

BETIM, A. C. O papel do professor diante da inclusão de um aluno surdo. Paraná, PDE 2013.

FERNANDES, Sueli. Fundamentos para educação especial

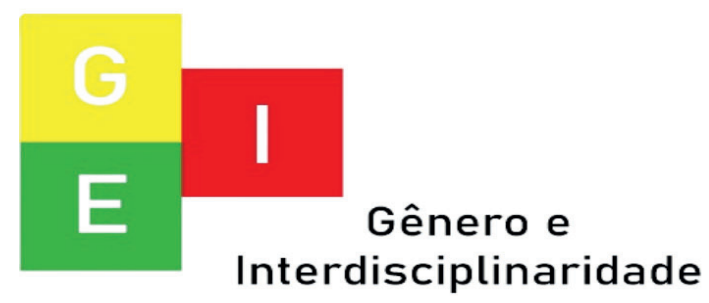


Vol. 02 - n 03 - ano 2021

Editora Acadêmica Periodicojs

- Curitiba: InterSaberes, 2013 MARCONI, Marina de Andrade;

- (Série Fundamentos da Educa- LAKATOS, Eva Maria. Fundação).

mentos de Metodologia Científi-

ca. $5^{\text {a }}$ ed., Editora Atlas. 2003.

FERNANDES, Sueli. Práticas de

letramentos na educação bilín-

MEGALE, Antonieta Heyden.

gue para surdos. Curitiba: SEED, 2006.

Bilinguismo e educação bilíngue: discutindo conceitos. Revista Virtual de Estudos da Lingua-

LAKATOS, E.M. MARCONI, gem - ReVEL. V. 3, n. 5, agosto M.A. Fundamentos de metodode 2005. In: ALBRES, N. A. SAlogia científica. 3 ed. São Paulo. RUTA, M. V. Programa curricuAtlas, 1991.

lar de língua brasileira de sinais para surdos. São Paulo: Ist, 2012.

LODI, A. C. B. Uma leitura enunciativa da língua brasileira de sinais: o gênero conto de fadas. DELTA [online]. vol. 20, n.2, pp. 281-310, 2004a. Disponível em: http://dx.doi.org/10.1590/ S0102-44502004000200005. In: ALBRES, N. A. SARUTA, M. V. Programa curricular de língua 2012. brasileira de sinais para surdos. São Paulo: Ist, 2012.

QUADROS, Ronice Muller. Educação de surdos: a aquisição da linguagem. Porto Alegre: Artes Médicas, 1997a. In: ALBRES,

N. A. SARUTA, M. V. Programa curricular de língua brasileira de sinais para surdos. São Paulo: Ist,

RODRIGUES, A. J. Contextos de aprendizagem e integração?

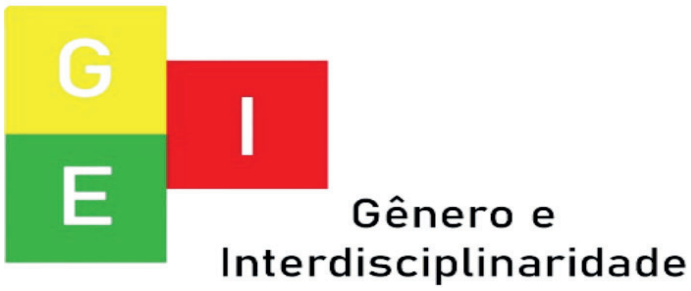


Inclusão de alunos com necessidades educativas especiais. São Paulo: Avercamp, 2003. In: BERGAMO, Regiane Banzzatto. Educação Especial: pesquisa e prática. - Curitiba: InterSaberes, 2012. - (Série Inclusão Escolar).

SÁNCHEZ, P. A. A educação inclusiva: um meio de construir escolas para todos no século XXI. Inclusão: revista da Educação Especial, Brasília, v.1, n.1, p.718.2005. In: FERNANDES, Sueli. Fundamentos para educação especial - Curitiba: InterSaberes, 2013 - (Série Fundamentos da Educação).

SILVA, Aline Maira da. Educação especial e inclusão escolar: história e fundamentos. - Curitiba: InterSaberes, 2012. (Série Inclusão Escolar).

https://www.ufpe.br/do- cuments/39399/2403144/ PER E I R A \% 3 B + S O U ZA+-+2019.1pdf/8320d506-68b2-4722-9477-6d3344b09427, acesso em 21 de janeiro de 2021. https://cultura-sorda.org/wp-content/uploads/2015/03/Fernandes_praticas_letramentos-surdos_2006.pdf, acesso em 22 de janeiro de 2021.

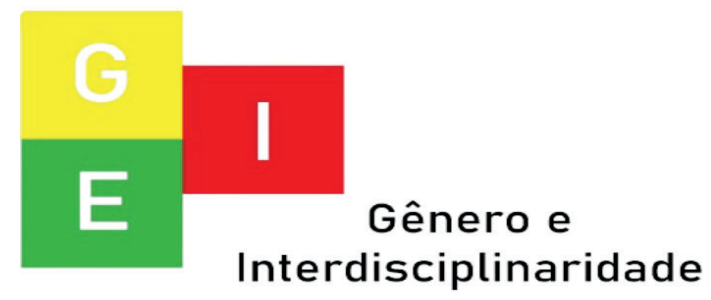

